\title{
Emerging Role of Clinical Preceptors (CPs) at a Private University, Karachi, Pakistan
}

\author{
Jacqueline Maria Dias ${ }^{1}$, Erum Lalwani ${ }^{1}$, Amina Aijaz Khowaja ${ }^{1}$, Yasmin Murad Mithani ${ }^{1}$ \\ ${ }^{1}$ The Aga Khan University School of Nursing and Midwifery, Pakistan \\ Correspondence: Jacqueline Maria Dias, The Aga Khan University School of Nursing and Midwifery, Stadium road P.O \\ Box 3500; Karachi, Pakistan.
}

Received: May 22, 2015

Accepted: June 14, 2017

Online Published: July 9, 2017

doi:10.11114/jets.v5i8.2529

URL: https://doi.org/10.11114/jets.v5i8.2529

\begin{abstract}
Clinical preceptors (CPs) play an integral role to prepare skilled, competent and caring student nurses to perform their future roles as members of the health care team. The aim of this study was to explore processes and effectiveness of the new role of clinical preceptors (CPs) in a low income country. A case study using Tellis (1997) approach was used. Data was collected from different viewpoints including, nursing administration, nursing services, co-faculty and students. The findings of the study will contribute to an in-depth understanding about the emerging role of CPs and operationalization of this role within the undergraduate nursing programme in Pakistan. The study findings endorse that CPs support clinical education of the nursing students' provided there is mentorship and a program for teaching and learning. Through this case study the authors demonstrated the complexities and challenges of introducing a new role. Additionally, factors like institutional support, resources and mentorship are vital elements to support the new emerging role of CPs. It is envisioned that this new role can be replicated in other health care disciplines locally and regionally.
\end{abstract}

Keywords: clinical preceptor, undergraduate nursing programme, faculty shortage, mentorship, institutional support

\section{Introduction}

In 2013, the authors of this paper were tasked with developing a new role for CPs. The development of this role was influenced by migration. Over the span of a year, ten faculty members migrated to North America. Thus, student learning was compromised in the clinical setting. Regulatory bodies governing nursing ensure the quality of clinical teaching by keeping the faculty student ratio as 1:10 (West et al, 2009). With the introduction of the new role of CPs the faculty student ratio would be maintained in the clinical courses. Initially two CPs were hired. In order to understand the entire process of the emerging role of CPs at a private university a case study approach was utilized.

\section{Literature Review}

The clinical environment is an integral part of the nursing curriculum where students receive hands on skills training and transition into professional practice. Therefore, it is important that students receive support for the integration of theory into practice. The literature provides plenty of evidence that CPs build a bridge between the nursing curriculum and the clinical (Palmer, Cox Callister, Johnsen \&Matsumura, 2005). CPs promote student learning, critical thinking, and socialization into the nursing profession (Block \& Sredl, 2006). The role of CPs has been well documented in the literature as guiding, teaching, supporting, and evaluating the student nurse in the clinical environment (Trede, Sutton, Bernoth, 2015). The CP facilitates the development of competence and confidence in the students as they make their transition into the real world. The concept of CPs in baccalaureate nursing education has been recommended as a substitute for clinical teaching. CPs have been widely adopted by nursing schools worldwide and seen as an answer to the growing worldwide shortage of nursing faculty (West et al, 2009, Trede, Sutton \& Bernoth, 2015, \& DeMeester, Hendricks, Stephenson \& Welch, 2017).

\section{Purpose}

The purpose of this study was to understand the emerging role of the CPs in the undergraduate nursing program at a private university. The new role was envisioned to overcome the shortage of nursing faculty and to be compliant with nursing regulations for providing clinical teaching to students. 


\section{Methodology}

The case study design was used. The case study design involve vigorous exploration of a single unit of study such as person, a very small number of subjects, a group or an institution (Burns \& Groove, 2007). Two CPs were hired for the period of July 2013 to November 2013 at a private university school of nursing and were the central to the case study. They had provided clinical preceptor-ship to year II Baccalaureate nursing students and served as a single case (i.e. clinical preceptor-ship role). Case studies analyze and understand the issues that are important to the historical development or circumstances of the entity under study (Polit \& Beck, 2008). Therefore the case study design was considered most appropriate to understand the evolution and effectiveness of the role of CPs. Using Tellis (1997) approach data was collected through interviews and Focus Group Discussions (FDGs).

\section{Ethical Consideration}

Institutional permission and ethical review clearance were obtained before collecting data for the study. Informed consent was obtained from each of the participants of the interviews and FGDs. Voluntary participation was encouraged and participants were assured that they can withdraw from the study at any point. The participant's confidentiality and anonymity was maintained throughout the study.

This study used Tellis (1997) six steps to understand the emerging role of CP. The six steps included in Figure 1;

\section{Tellis steps (1997)}

1. Research questions

2. Select cases and gather data

3. Data collection process planning

4. Collect data in the field

5. Data analysis

6. Report preparation

Figure 1. Six steps to understand the emerging role of $\mathrm{CP}$

The case study explored the following five research questions:

1. Why was there a need for CPs in the undergraduate programme?

2. What processes were used to select the CPs for the undergraduate programme?

3. What preparations were made to bring clinical preceptor-ship role in the undergraduate nursing programme?

4. How effective was the clinical preceptor-ship role in the undergraduate nursing programme?

5. What were the recommendations provided by the stakeholders for implementing the clinical preceptor-ship role in the undergraduate nursing programme?

To answer these questions, information was collected from various stakeholders through FDGs and interviews about the emerging role of CPs.

\section{Interviews}

Total of four interviews were conducted. This included interviews with nursing administration both at School of nursing and Nursing Services. Each interview took 20-30minutes. Semi- structured interviews were conducted with the help of an interview guide by one of the investigators.

\subsection{FGDs}

Three FGDs were held. Out of three, two FGDs were conducted with students who were supervised by CPs. The third FGD was conducted with co-faculty working with CPs in the same course. Each FGD was approximately 30-45 minutes. Each FGD had 6-8 participants. All FDGs were conducted with the help of an interview guide. These qualitative findings have been discussed in details in another publication emanating from this study.

\subsection{Data Analysis and Report Preparation}

Data for this study was analyzed by answering the five research questions.

\section{Q1. Why was there the need for clinical preceptors in the undergraduate programme?}

The Institute of Medicine Report (2009) testified the shortage of health professions faculty is one of the major challenges facing the twenty-first century; so innovative solutions must be sought to meet the objectives of the nursing 
education (IOM, 2009). Faculty attrition within nursing is a common feature worldwide and in Pakistan as well (Kowalski et al, 2007). This idea of the role of CP was conceived by the nursing management at school of nursing. It was envisioned that the $\mathrm{CP}$ would work closely with the course faculty as faculty extenders.

The nursing leadership from the institution reported that nursing student's clinicals were compromised with the resignation of faculty members within a year. Another senior management person indicated this new role the CPs would be able to take care of the students while on clinical in order to ensure quality and keep the regulatory compliance of faculty student ratio of 1:10.

\section{Q2. What processes were used to select the clinical preceptors?}

Hiring competent CPs was the mandate for introduction of this new role. Brain storming sessions were done with the nursing management at school of nursing, stakeholders in Nursing Services and Human Resource Department for the execution of this new role. The two CPs were hired for the period from July 2013 to November 2013. It is imperative that the role of the CP is conceptualized early in the process and shaped by organizational impact (Trede, Sutton \& Bernoth, 2016). Introduction of a new role in the organization was challenging. We needed to engage stakeholders in order to bring this new role to fruition. This included meetings with the Director of Nursing Services and nursing unit manager where the CPs would provide clinical supervision for the students Meetings were held to clarify misconceptions and for organizational well-being. Role ambiguity can result from lack of role clarity and a general misunderstanding of what is expected of the CP (Trede, Sutton \& Bernoth, 2016). Supportive leadership is instrumental to setting up a new role. From an administrative standpoint the CPs were hired one month prior to the start of the semester and they were retained one month after the semester ended so that they could complete clinical evaluation forms and give student feedback.

The CPs provided clinical preceptor-ship to year II BScN students. It was expected that a CP would take care of a group of up to 12 students in one clinical area. The $\mathrm{CP}$ had a strong clinical background with four years of continuous employment in the same clinical agency where they provided clinical supervision.

\section{Q3. What preparations were made to bring clinical preceptor-ship role in the undergraduate nursing programme?}

Socialization is an integral component for a new role (Phuma-Ngaiyaye, Bvumbwe \& Chipeta, 2017). This was achieved by introductory meetings with the nursing management at School of Nursing including the Dean, Directors and faculty at Faculty Council. In addition, the CP's were introduced to the Nursing Services Director and Nurse Managers at the clinical agency in terms of their new role and responsibilities.

Along with socialization into a new role, skill acquisitions are another vital element. The CP's were provided a two week orientation to the clinical agency under the mentorship of a senior faculty in order to familiarize themselves in their new role as CPs. Billings \& Halstead (2016) strongly recommend an in-depth orientation. Also, meetings were arranged with the co faculty to understand the clinical components of the course grid, the clinical objectives of the students and the clinical evaluation tool used on clinicals.

Furthermore, a group consisting of the director and coordinator of the program provided support and ongoing mentorship. Fortnightly meetings were held to discuss ongoing issues and concern both by the CPs and co- faculty. Furthermore, CPs were provided with access to library, computer and office space, as well as an introductory short course on teaching and learning, and mentorship and on-going support for dealing with difficult students.

Q4. How effective is the clinical preceptor-ship role in the undergraduate nursing programme?

In this study effectiveness was measured through the, students, co faculty teaching in same course and nursing administration through interviews and FDGs.

\subsection{Report of Students' FDG}

Students during FDGs stated that CPs' prior knowledge and their clinical experience were valuable assets to perform their role effectively. Students felt that skills such as intravenous canualation, catheterization, medication, dressing, suctioning, and nasogastric tube feeding were most anxiety provoking especially doing it for the first time. However, CPs non-threatening attitude on the clinicals reduced students' anxiety and fears of harming patients by their skills performance. Moreover, their updated clinical experience which amounted to four years helped students to perform skills with more comfort, which eventually enhanced students' self-confidence to do various nursing procedures.

Students shared that CPs used an adult approach to dealing with various clinical scenarios and utilized a variety of clinical teaching methods such as conducting supervised practice session in skills lab, and then asking students to perform on patients under their supervision. Students also added that whenever, any new learning opportunity or unique case arose in the unit, CPs always called students in a group and would discuss in detail the ramifications of these special cases. Additionally, the CPs would discuss identified cases in post conferences as well. Moreover, CPs were able 
to transfer learning from skills lab to practice areas like taking vitals manually in skills lab but facilitated students in the unit to take vitals electronically. As the CPs had worked previously in the same clinical agency they had good rapport with the unit staff. This made it easier for the students to work collaboratively and communicate effectively with the health care team in the unit.

\subsection{Report of Faculty FDG}

Co- faculty members stated CPs were receptive in taking assignments, initiative, seeking guidance when needed and accepted delegated tasks. They added that CP's are competent in skills specifically in the clinical areas where they had been working as part of their professional practice.

\subsection{Report from Administration}

The nursing administration viewed the hiring of CPs as a positive initiative for the school of nursing Furthermore, from an accreditation point of view the school of nursing was in compliance with the regulatory bodies. In addition, they felt this initiative served as a cost cutting measure as the CPs were hired for only a semester with no additional benefits.|

\subsection{Challenges Faced by Students and Co Faculty and Administration}

The students and co -faculty encountered similar challenges. These included facilitating students in integration of theory into practice on the clinicals, and provision of timely and effective feedback. In addition, co-faculty reported the CPs had some difficulty in maintaining anecdotal records of the students, dealing with difficult students and the quality of their work reflected lack of experience and lack of planned mentorship As Schriner (2007) points out that if one is not educationally prepared to be a teacher then this is picked up by students who doubt their abilities as educators.

From the nursing administration standpoint as this position was only for a semester the identified CPs left at the end of their contract. For the next semester new CPs had to be taken on board. Therefore, sustainability of this position remained a challenge.

\subsection{Future Considerations}

Every new initiative has its complexities and challenges. Formal training in teaching and learning with emphasizes on clinical teaching and feedback should be provided to CPs before the start of the semester. Additionally, for improving integration of theory into practice, $\mathrm{CPs}$ should be given course modules ahead of the clinical, so they come prepared for the clinical assignment. Furthermore, co-faculty members recommended shadowing of preceptors on clinical by senior faculty for at least one semester before they independently supervised students. It was also suggested, that for better performance mentorship should be provided to the CPs on an ongoing basis. Students also recommended that CPs should also be evaluated and given feedback on their performance. Additionally, institutional support and engagement of stakeholders are vital elements to support the new role.

\section{Conclusion}

In summary, nursing faculty shortage will continue to persist in Pakistan. The introduction of this novel role of CPs was acknowledged by nursing administration, stakeholders, co-faculty and students. It was suggested by the case study findings that CPs are clinically competent and experienced which contributed extensively to student learning. The researchers are of opinion that along with mentoring and shadowing there is a dire need to introduce a course on clinical teaching with a focus on feedback and dealing with difficult students. Given the success of this innovation, the university has employed nine more CPs in the undergraduate nursing program to compensate for the nursing faculty shortage on clinicals. However, it is worth mentioning that from the time this study was undertaken to the time of the publication two of the authors have migrated to North America.

\section{References}

Billings, D. M., \& Halstead, J. A. (Eds.) (2016). Teaching in nursing: a guide for faculty St. Louis, Mo.: Saunders/Elsevier

Block, V., \& Sredl, D. (2006). Nursing Education and Professional Practice. Journal for Nurses in Staff Development (JNSD), 22(1), 23-28. https://doi.org/10.1097/00124645-200601000-00006

Burns, N., \& Groove, S. K. (2007). Understanding Nursing Research ( $4^{\text {th }}$ Ed). Saunders: St Louis

DeMeester, D., Hendricks, S., Stephenson, E., \& Welch, J. (2017). Student, Preceptor, and Faculty Perceptions of Three Clinical Learning Models. Journal of Nursing Education, 56(5), 281-286. https://doi.org/10.3928/01484834-20170421-05

Kowalski, K., Horner, M., Carroll, K., Center, D., Foss, K., Jarrett, S., \& Kane, L. (2007). Nursing Clinical Faculty Revisited: The Benefits of Developing Staff Nurses as Clinical Scholars. The Journal of Continuing Education in Nursing, 38(2), 69-75. https://doi.org/10.3928/00220124-20070301-08 
Palmer, S. P., Cox, A. H., Callister, I. C., Johnsen, V., \& Matsumura, G. (2005). Nursing Education and Service Collaboration; Making a difference in the clinical learning environment. The Journal of Continuing Education in Nursing, 36, 271-276.

Phuma-Ngaiyaye, E., Bvumbwe, T., \& Chipeta, M. (2017). Using preceptors to improve nursing students' clinical learning outcomes: A Malawian students' perspective. International Journal of Nursing Sciences, 4(2), 164-168. https://doi.org/10.1016/j.ijnss.2017.03.001

Polit, D. F., \& Beck, C. T. (2012). Essentials of nursing research: Generating and Assessing Evidence for Nursing Practice (9th ed.). New York: Lippincott Williams \& Wilkins.

Schriner, C. (2007). The influence of culture on clinical nurses transitioning into the faculty roles. Nursing Education Perspectives, 28(3), 145-149.

Tellis, W. M. (1997). Application of a Case Study Methodology. The Qualitative Report, 3(3), 1-19. Retrieved from http://nsuworks.nova.edu/tqr/vol3/iss3/1

The Future of Nursing; Focus on Education. Institute of Medicine. National Academy of Sciences. (2009). (http//.www.iom.edu/nursing)

Trede, F., Sutton, K., \& Bernoth, M. (2016). Conceptualizations and perceptions of the nurse preceptor's $\quad$ role: A scoping review. Nurse Education Today, 36, 268-274. https://doi.org/10.1016/j.nedt.2015.07.032

West, M., Borden, C., Bermudez, M., Hanson-Zalot, M., Amorim, F., \& Marmion, R. (2009). Enhancing the Clinical Adjunct Role to Benefit Students. The Journal of Continuing Education in Nursing, 40(7), 305-310. https://doi.org/10.3928/00220124-20090623-05

\section{Copyrights}

Copyright for this article is retained by the author(s), with first publication rights granted to the journal.

This is an open-access article distributed under the terms and conditions of the Creative Commons Attribution license which permits unrestricted use, distribution, and reproduction in any medium, provided the original work is properly cited. 